\title{
The role of augmentative and alternative communication for children with autism: current status and future trends
}

This article was published in the following Dove Press journal:

Neuropsychiatric Disease and Treatment

19 September 2016

Number of times this article has been viewed

\author{
Teresa lacono' \\ David Trembath ${ }^{2}$ \\ Shane Erickson ${ }^{3}$ \\ 'Living with Disability Research \\ Centre, La Trobe University, Bendigo, \\ VIC, Australia; ${ }^{2}$ Menzies Health \\ Institute Queensland, Griffith \\ University, Gold Coast, QLD, \\ Australia; ${ }^{3}$ Living with Disability \\ Research Centre, La Trobe University, \\ Melbourne, VIC, Australia
}

Correspondence: Teresa lacono Living with Disability Research Centre, La Trobe Rural Health School, 102 Arnold Street, Bendigo, VIC 3552, Australia Tel +6I3 5449 9I I0

Email t.iacono@latrobe.edu.au
Background: Augmentative and alternative communication (AAC) interventions are used for children with autism, often as stand-alone communication interventions for those who are minimally verbal. Our aim was to synthesize the evidence for AAC interventions for children (up to 21 years), and then consider the role of AAC within established, comprehensive, evidencebased autism interventions targeting learning across multiple developmental domains.

Design: We completed a systematic search of three databases (OVID Medline, PsycINFO, ERIC) as well as forward citation and hand searches to identify systematic reviews of AAC intervention efficacy research including children with autism, published between 2000 and March 2016 in peer-reviewed journals. Data pertaining to the quality indicators of included studies, effect sizes for intervention outcomes, and evidence for effectiveness were extracted for descriptive analysis.

Results: The search yielded 17 systematic reviews. Most provided indicators of research quality for included studies, of which only relatively few provided conclusive results. Communication targets tended to be focused on teaching children to make requests. Still, effect size measures for included studies indicated that AAC was effective to highly effective.

Conclusion: There is growing evidence for the potential benefits of AAC for children with autism, but there is a need for more well-designed studies and broader, targeted outcomes. Furthermore, a lack of evidence for the role of AAC within comprehensive intervention programs may account for a tendency by autism researchers and practitioners to neglect this intervention. Attempts to compare evidence for AAC with other interventions for children with autism, including those in which the use of AAC is delayed or excluded in pursuit of speechonly communication, must take into account the needs of children with the most significant learning needs. These children pose the greatest challenges to achieving large and consistent intervention effects, yet stand to gain the most from AAC interventions.

Keywords: autism, augmentative and alternative communication, intervention, research synthesis

\section{The role of augmentative and alternative communication for children with autism: current status and future trends}

Over recent decades there has been increasing research that has provided empirical support for the use of augmentative and alternative communication (AAC) by children with autism. These children demonstrate pervasive deficits in social communication as well as repetitive and restricted behaviors. ${ }^{1}$ AAC encompasses various modalities that can replace or augment a person's speech and other existing communication skills. 
These modalities are either unaided, usually in the form of manual signs, or aided, with systems including graphic symbols displayed on communication boards and in books, or devices relying on technology, such as speech generating devices (SGD), including mobile technologies. ${ }^{1}$ About $30 \%$ of children with autism who fail to develop speech skills sufficient for daily communication functions ${ }^{2}$ and have the most severe disability stand to benefit most from AAC. ${ }^{1}$ These children are at particular risk of developing problem behaviors, limited academic learning, lack of job prospects, poor social networks, and mental health problems as they move from childhood to adulthood. ${ }^{1,3}$

Aided AAC, in particular, would seem well suited to individuals with autism because it has been argued that they process visual information more easily than auditory information. ${ }^{4,5}$ Despite the growth of research influencing clinical applications, ${ }^{1}$ evidence for AAC as an autism intervention has been identified as emerging only, rather than established by the National Autism Centre (NAC) ${ }^{6,7}$ in the US. Emerging interventions are those found by a panel of expert reviewers to be supported by some, but without sufficient high-quality studies indicating their benefits for individuals with autism. ${ }^{6,7}$ This category contrasts with established interventions for which the NAC panel found sufficient high quality, quantity, and consistency of research evidence of treatment effects. Of interest was the separate consideration of manual signs (also rated as emerging) and visual schedules (established), both of which are considered forms of AAC within the field, ${ }^{8,9}$ and these were reported by Wendt and Mirenda and Brown, respectively. Further, there are indications from the autism field that AAC has been viewed as having only a limited role (eg, incorporated only after speechalone instruction has failed to produce an adequate intervention response, as in the Early Start Denver $\mathrm{Model}^{10}$ ), or no role (eg, Pivotal Response Training ${ }^{11}$ ) in some comprehensive intervention programs. A failure to consider the benefits of AAC early in a child's comprehensive intervention program is at odds with decades of work from within the AAC field. The aim of this work has been to ensure that children with significant communication impairment are provided with communication support as early as possible. ${ }^{12}$

Any attempt to evaluate the role of AAC for children with autism and identify future avenues for its efficacious application requires consideration of research from across both AAC and autism fields. Within each field, research accumulated over the last 40 years has led to an increasing number of systematic reviews in an attempt to synthesize and evaluate the quality of research addressing specific topics. In AAC, such synthesis began around 1999, in an effort to apply evidence-based principles from medicine. ${ }^{13}$ Early reviews by Schlosser and Lee ${ }^{14}$ indicated gaps in research quality, particularly in failures to demonstrate generalization and maintenance or social validity (ie, the practicality of interventions and the social importance of outcomes).${ }^{15}$ Since then, a number of systematic reviews have been conducted with a specific focus on AAC and autism (eg, Ganz'1). In autism, similarly, systematic reviews have provided a means to synthesize and evaluate the quality of a large body of intervention research (eg, Howlin et $\mathrm{al}^{16}$ ), but perhaps none has been as comprehensive as that completed over a number of years by the expert panel of the NAC. 6,7

\section{Aim}

Our aim was to summarize the systematic reviews in AAC of relevance to children with autism to provide a comprehensive overview of the state-of-the-art in this area. Along with this, our further aim was to consider the role of AAC within the context of established interventions identified by the NAC. ${ }^{6,7}$ In particular, we sought to consider existing and potential points of convergence so as to move both fields forward in addressing the problems with social communication and behavior that impede academic learning by and social inclusion of children with autism.

\section{Method Identifying the reviews}

We adopted a combined approach to locate published reviews addressing AAC in children with autism, beginning with systematic searches of the databases OVID Medline, PsycINFO, and ERIC, and then conducting forward citation and hand searches of reference lists. ${ }^{17}$ Database search terms were autis* or autism spectrum disorders or ASD; AAC or augmentative and alternative, or augmentative communication or alternative communication, and limits were from 2000 (coinciding with the earliest systematic reviews in AAC) to March 2016, review articles, and papers published in English. After the removal of duplicates, a title and abstract review was conducted, deleting dissertations and book chapters, and other non-peer-reviewed journal publications, and reviews relating to facilitated communication, given that it has been evaluated as a non-evidencebased strategy ${ }^{6,18}$ Forward citations of early reviews $(n=5)$ yielded two additional reviews, and hand searches of reference lists of later reviews $(n=13)$ yielded eleven more. Following title and abstract reviews of retrieved papers, full-text papers were retrieved for 37 articles. The search and selection process are detailed in Figure 1.

Two of the authors then independently evaluated the retrieved full text articles against the following inclusion 


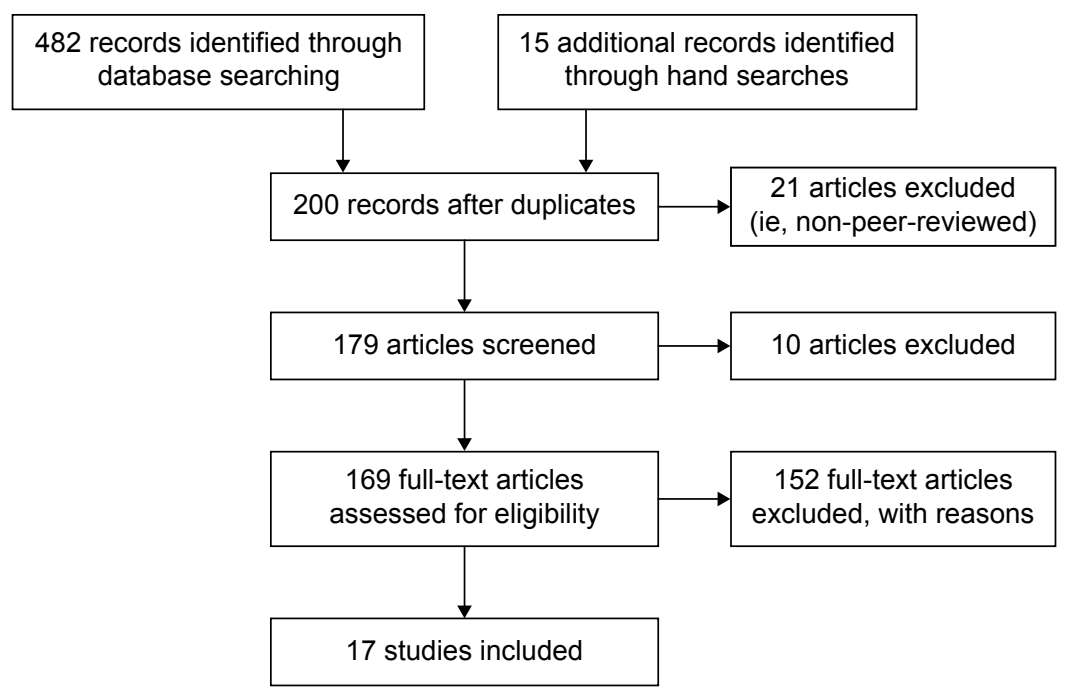

Figure I Flow chart of systematic search.

criteria: (1) a systematic search was conducted; (2) the review included one or more effect size metrics, with results reported in either aggregate form or for each included study, and/or a quality appraisal was conducted of included studies; (3) studies were of children with autism (up to 21 years, in line with the $\mathrm{NAC}^{6,7}$ ), or if other participant groups or older individuals were included, results for children with autism could be extracted; and (4) all included studies addressed some aspect of the efficacy of AAC as an intervention or part of an intervention.

\section{Results}

\section{Articles included and data extraction}

Seventeen systematic reviews were included (with 100\% agreement between authors). The aims, type of systematic review and effect size metric (if used), publication period of included studies, inclusion criteria, quality indicator or appraisal method, and key findings were extracted. This information is presented in Table 1, with studies organized according to key themes relating to review aims. These themes were (1) overall effectiveness of various types of AAC and comparison of effectiveness across variables $(n=5)$; (2) evaluation of the AAC instructional package, Picture Exchange Communication System (PECS) ( $n=5)$; (3) effects on speech ( $n=2)$; (4) use of high technology, including SGD and newer mobile technologies of iPods ${ }^{\circledR}, \mathrm{iPads}^{\circledR}(\mathrm{n}=4)$; and (5) partner instruction $(n=1)$.

\section{Quality indicators}

Most included reviews applied some measure of quality through appraisals that varied in detail: these are summarized in Table 2. These appraisals provided an evaluation of the rigor of studies, thereby indicating the confidence with which outcomes could be attributed to the AAC intervention being investigated. Across the reviews, most studies were of experimental single case designs (ESCD), and in fact, seven reviews had this design as an inclusion criterion. ${ }^{19,20,22,26-28,36}$ Strategies to address the certainty of the evidence varied. In some reviews, only studies in which experimental control was demonstrated were included, thereby focusing on internal validity, such as through the type of design used..$^{35}$ In other reviews, studies were categorized according to the extent to which evidence was conclusive. ${ }^{34}$ More detailed appraisals, such as those based on indicators of quality of $\mathrm{ESCD}^{37}$ or group studies ${ }^{38}$ addressed internal validity and aspects of external validity, with indicators taken from Horner et $\mathrm{al}^{37}$ including social validity. In five studies, certainty of evidence was not addressed directly ${ }^{19,28,36}$ or specific design features, such as inclusion of treatment fidelity measures ${ }^{27}$ or broader indicators, were simply noted. ${ }^{30}$

Information from reviews that did include some form of critical appraisal suggests that only few studies provided conclusive results, with more providing evidence described as preponderant in one coding scheme: that is, based on studies with only minor flaws (Table 2). In some reviews, however, a large proportion of studies were evaluated as providing inconclusive results (eg, Schlosser and $\mathrm{Koul}^{32}$ ).

\section{Measures of effect size}

There was debate evident across reviews about the most appropriate means to measure effect size for ESCD. Ganz et al, ${ }^{19,20,28,36}$ for example, argued that the Improvement Rate Difference index had advantages over the frequently used Percentage of Nonoverlapping Data points, including that it 


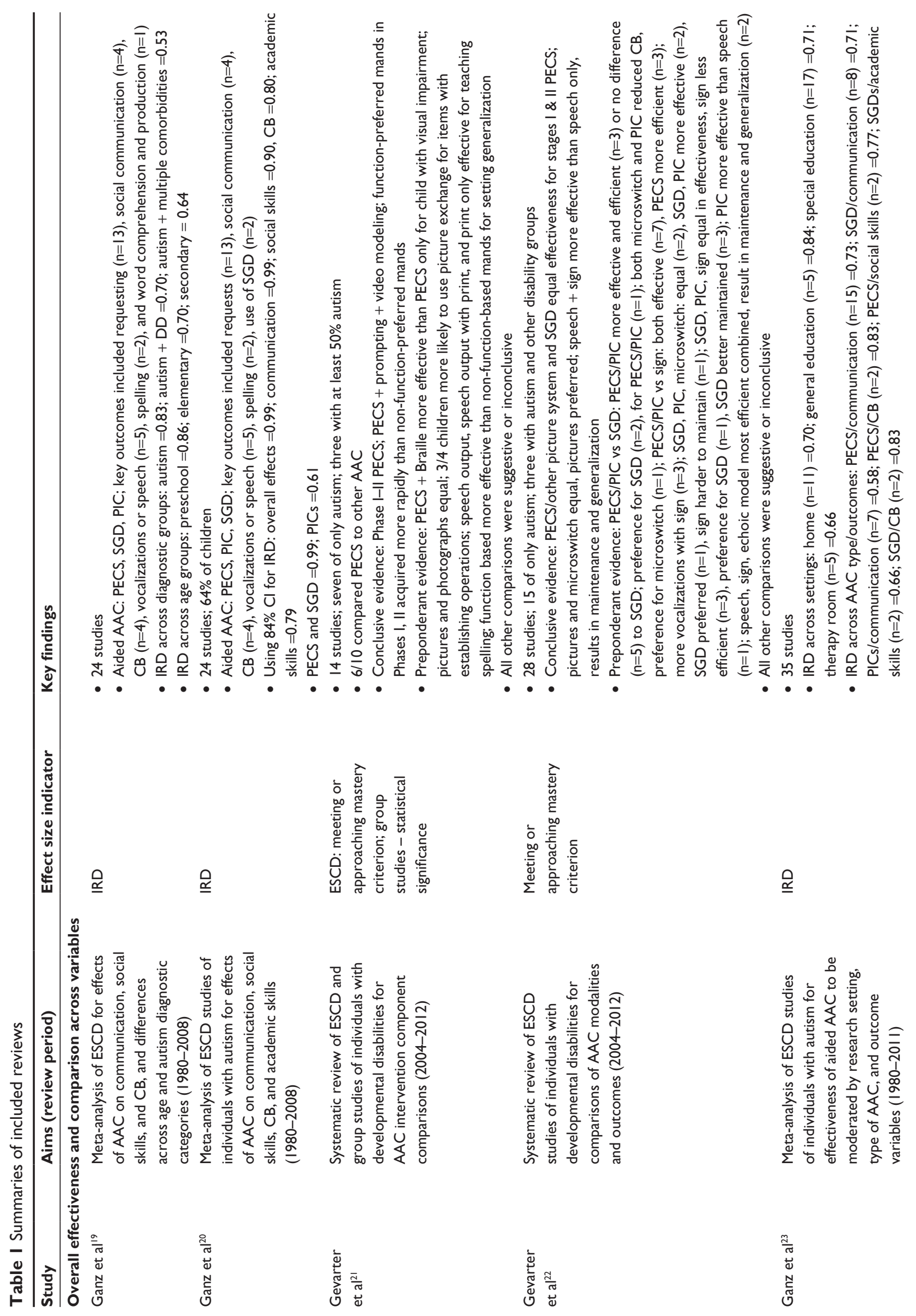




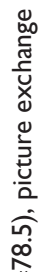

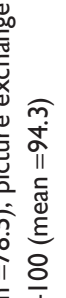

宽 $\frac{1}{\infty}$

前

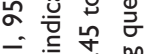

ํํำ

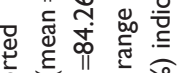

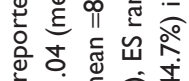

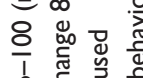

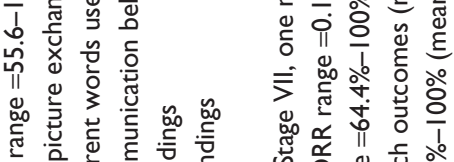

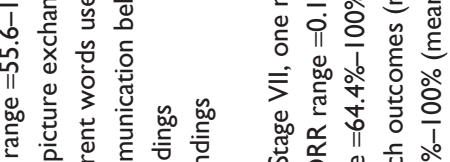

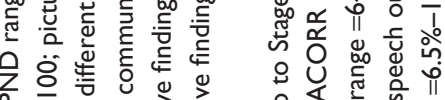

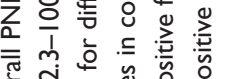

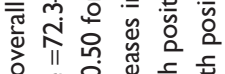

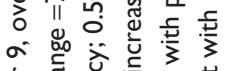

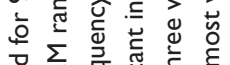

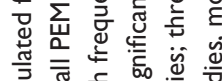

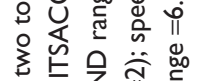

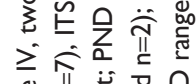

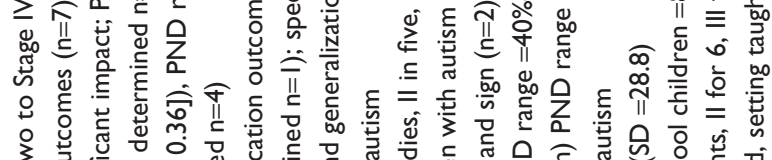

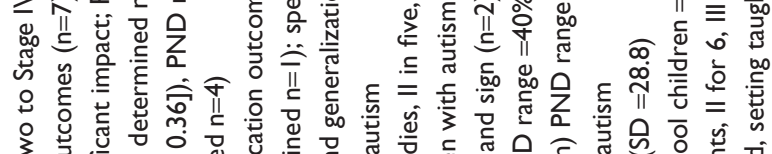

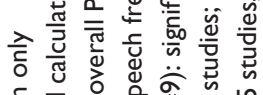

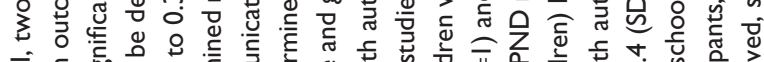

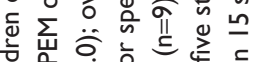

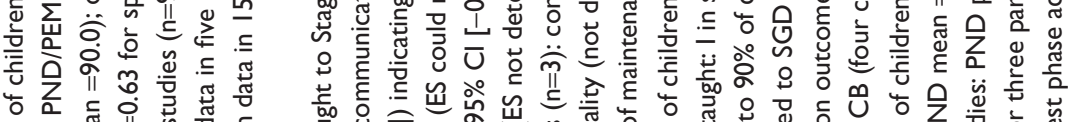

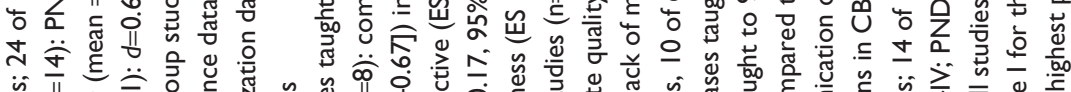

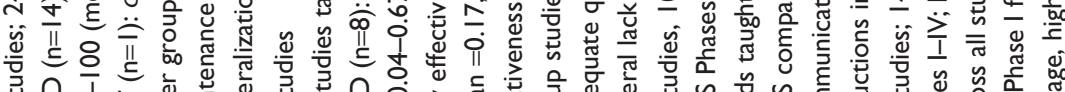

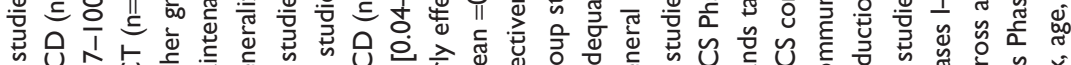

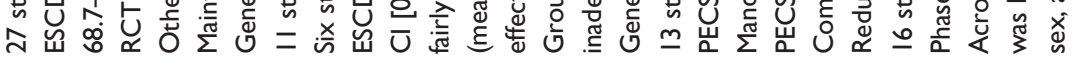

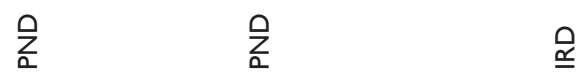

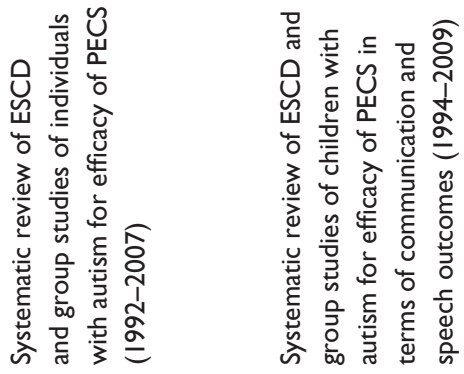

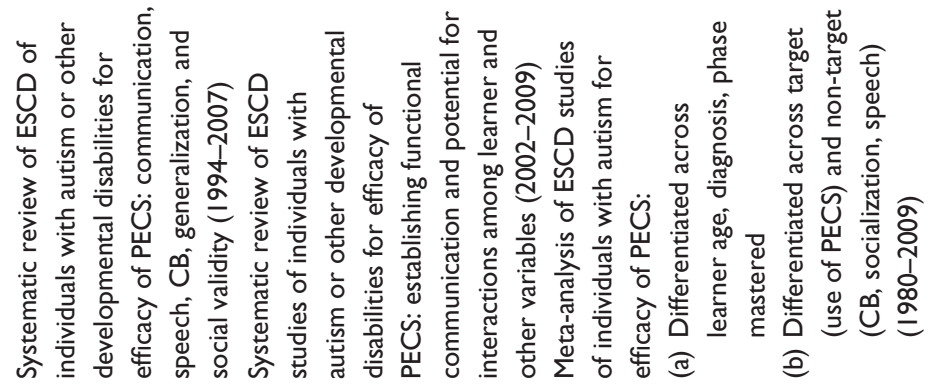

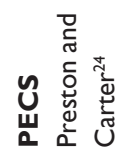

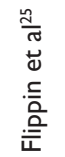

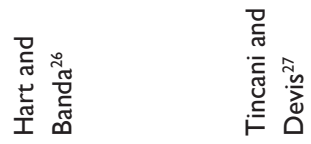

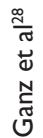




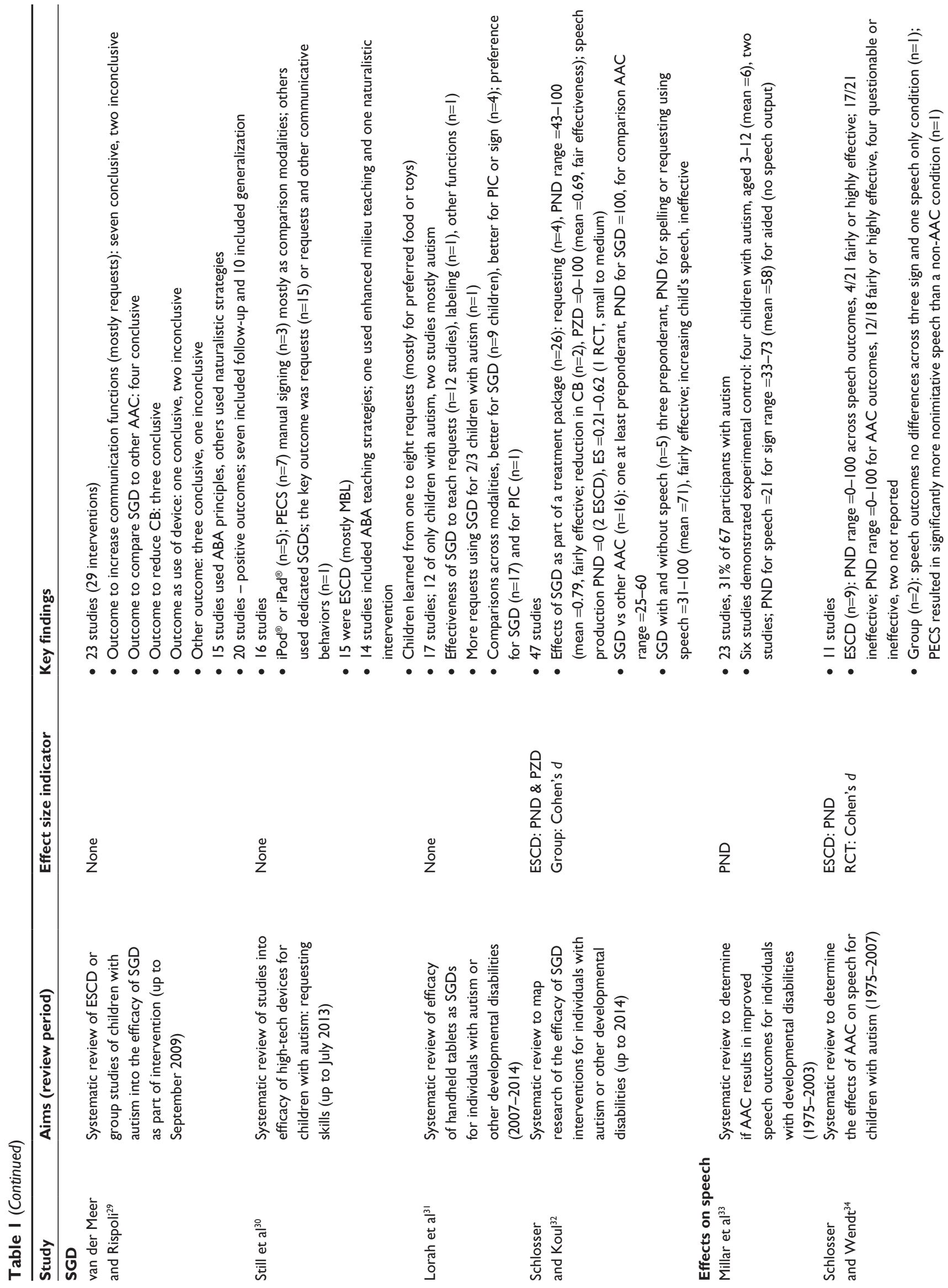




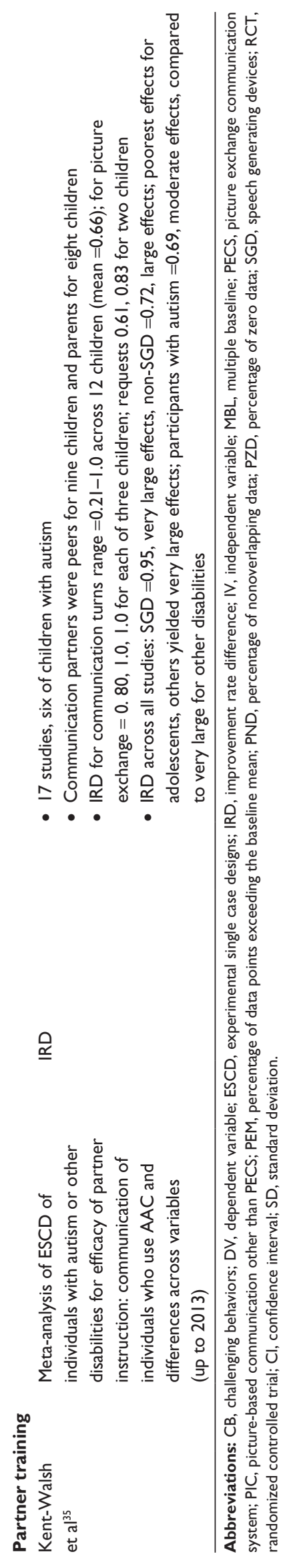

allowed confidence intervals to be determined. Regardless of the index used, effect sizes enabled the aggregation of outcomes across studies, as well as a means for evaluating differential effects across variables, which have been reported in Table 1.

\section{Effectiveness of AAC}

Even taking into consideration concerns about study quality, the evidence presented across reviews, as summarized in Table 1, indicates that, overall, AAC has been found to be effective to highly effective for children with autism according to the metrics applied (Table 2). The reviews included favored aided AAC, with most evidence supporting the use of PECS, a manualized instructional package for teaching individuals to exchange pictures for desired wants - that is, to learn to request (described by Flippin et $\mathrm{al}^{25}$ ) - and SGD (including newer mobile tablets and other handheld devices), with evidence being weaker for other picture-based systems or manual signs. In fact, studies of manual signs were included in systematic reviews only when compared to aided systems. ${ }^{22,26,31,33,34}$ It has been suggested that manual signs may pose a number of challenges, including being difficult to produce in the presence of motor difficulties and reduced use of gestures and/or poor imitation skills seen in many children with autism. ${ }^{20,42}$ On the other hand, arguments that aided AAC suits strengths in processing visual material ${ }^{26,28}$ have been made because pictures provide a concrete representation to which a child can refer back. ${ }^{20}$ This premise was questioned in a recent study, in which it was found that children with autism, unlike children with global developmental delays or without disability, ${ }^{43}$ did not show improved task performance when asked to complete a series of short instructions under speech + pictures vs speech-only experimental conditions.

Effectiveness of AAC appears overwhelmingly to relate to teaching functional communication, with a focus on requests. ${ }^{20}$ As shown in Table 1, key targeted outcomes were predominantly requests across the included reviews; this was particularly the case for studies of PECS, designed to teach requests through picture exchange. ${ }^{25}$ A tendency to target requests may reflect the relative ease with which they can be taught to children with autism in light of their strengths in behavioral regulation (ie, communication to gain desired objects or actions, usually through requests), as opposed to deficits in social interaction. ${ }^{1}$ In particular, much research has focused on the efficacy of PECS, designed specifically for children with autism (Table 1). Aggregation of data through meta-analysis indicates that the first three stages of PECS are effective 
Table 2 Effect size and quality indicators

\begin{tabular}{|c|c|c|}
\hline Indicator & Definition & Categories \\
\hline \multicolumn{3}{|l|}{ Effects sizes } \\
\hline PND $^{39}$ & $\begin{array}{l}\text { Percentage of nonoverlapping data - } \\
\text { percentage of data points that are above the } \\
\text { highest baseline data point }\end{array}$ & $\begin{array}{l}\text { Highly effective }=91 \%-100 \% \\
\text { Effective }=71 \%-90 \% \\
\text { Questionable }=51 \%-70 \% \\
\text { Ineffective }=<51 \%\end{array}$ \\
\hline PEM $^{40}$ & $\begin{array}{l}\text { Percentage of treatment data points that are } \\
\text { above the median baseline data point }\end{array}$ & $\begin{array}{l}\text { Highly effective }=91 \%-100 \% \\
\text { Moderately effective }=70 \%-89 \% \\
\text { Minimally effective }=50 \%-69 \% \\
\text { Ineffective }=<50 \%\end{array}$ \\
\hline PZD & $\begin{array}{l}\text { The first data point in the treatment that } \\
\text { equals } 0 \text { and calculating the percentage of data } \\
\text { points in treatment that stay at } 0 \text { from then on } \\
\text { (used when the aim is to reduce a behavior) }\end{array}$ & $\begin{array}{l}\text { High effectiveness }=81 \%-100 \% \\
\text { Fair effectiveness }=55 \%-80 \% \\
\text { Questionable effectiveness }=18 \%-54 \% \\
\text { Ineffectiveness }=<18 \%\end{array}$ \\
\hline IRD & $\begin{array}{l}\text { IRD - the improvement rate of the baseline } \\
\text { phase is subtracted from the improvement } \\
\text { rate of the treatment phase }\end{array}$ & $\begin{array}{l}\text { Large or very large effects }=>0.75 \\
\text { Large effects }=0.7 \mathrm{I}-0.75 \\
\text { Moderate effects }=0.5 \mathrm{I}-0.70 \\
\text { Very small or questionable effects }=<0.50\end{array}$ \\
\hline ITSACORR & $\begin{array}{l}\text { Software program providing an F statistic and } \\
\text { tests of changes in intercept and in slope for } \\
\text { ESCD data, calculated as Glass's delta }{ }^{41}\end{array}$ & $\begin{array}{l}\text { Interpreted according to confidence intervals, } \\
\text { determined for each outcome within included } \\
\text { studies }\end{array}$ \\
\hline Cohen's d & $\begin{array}{l}\text { Used for inferential statistics applied to } \\
\text { group designs }\end{array}$ & $\begin{array}{l}\text { Small effect }=0.2-0.5 \\
\text { Moderate effect }=0.5-0.8 \\
\text { Large effect }=>0.8\end{array}$ \\
\hline Quality indicators & & \\
\hline $\begin{array}{l}\text { Indicators of rigor of ESCD } \\
\text { based on Horner et a }{ }^{37}\end{array}$ & $\begin{array}{l}\text { Indicators for core elements of participant } \\
\text { and setting descriptions, dependent and } \\
\text { independent variables, baseline, experimental } \\
\text { control/internal validity, external validity, and } \\
\text { social validity }\end{array}$ & $\begin{array}{l}\text { Various ways to apply these were used across } \\
\text { studies, some with scoring systems } \\
\text { aStrong }=90 \%+ \\
\text { Adequate }=75 \%-90 \% \\
\text { Inadequate }=<75 \%\end{array}$ \\
\hline $\begin{array}{l}\text { Indicators of rigor for } \\
\text { experimental and quasi- } \\
\text { experimental group studies } \\
\text { based on Gersten et al }{ }^{38}\end{array}$ & $\begin{array}{l}\text { Indicators for core elements of underlying } \\
\text { study rationale, participants/sampling, } \\
\text { intervention descriptions and fidelity, outcome } \\
\text { measures, data analysis }\end{array}$ & $\begin{array}{l}\text { Strong }=90 \%+ \\
\text { Adequate }=75 \%-90 \% \\
\text { Inadequate }=<75 \%\end{array}$ \\
\hline $\begin{array}{l}\text { Certainty of evidence } \\
\text { (four groups) }\end{array}$ & $\begin{array}{l}\text { Features of the study are examined in terms } \\
\text { of design, IOA, and treatment integrity }\end{array}$ & $\begin{array}{l}\text { Conclusive evidence: sound design and at least } \\
\text { adequate IOA and treatment integrity } \\
\text { Preponderant evidence: minor design flaws and } \\
\text { at least adequate IOA and treatment integrity } \\
\text { Suggestive evidence: strong design or minor design } \\
\text { flaws but inadequate IOA and/or treatment integrity } \\
\text { Inconclusive: fatal design flaws }\end{array}$ \\
\hline $\begin{array}{l}\text { Certainty of evidence } \\
\text { (dichotomous) }\end{array}$ & $\begin{array}{l}\text { Quality of the study is considered to } \\
\text { determine if experimental control has been } \\
\text { demonstrated }\end{array}$ & $\begin{array}{l}\text { Conclusive: recognized experimental design through } \\
\text { systematic introduction and removal (eg, } \mathrm{ABAB} \text { ) or } \\
\text { sequential introduction (eg, } \mathrm{MBL} \text { ) of intervention } \\
\text { Inconclusive: nonexperimental design }\end{array}$ \\
\hline
\end{tabular}

Note: andicates these categories used only by Flippin et al, ${ }^{25}$ others applied the indicators more descriptively.

Abbreviations: PND, percentage of nonoverlapping data; PEM, percentage of data points exceeding the baseline mean; PZD, percentage of zero data; IRD, improvement rate difference; IOA, inter-observer agreement; ESCD, experimental single case designs; MBL, multiple baseline.

to highly effective in teaching children to request preferred items. ${ }^{24-27}$ In stages IV and V of PECS, the use of requests in multiword utterances is targeted, with other communicative functions not introduced until the final stage VI. ${ }^{25}$ Ganz et $\mathrm{al}^{28}$ found large effects for the only two included studies in their review in which all stages were taught, but improvement rate differences ranged from 0.15 to 0.94 , indicating some effects were questionable (Table 2).
AAC has also been found effective for reducing challenging behaviors. ${ }^{20,21,26,28,29,32,36}$ Interventions reported in Table 1 were of functional communication training, in which AAC was taught as a replacement behavior. ${ }^{1}$ In addition, reduction in challenging behavior has been examined as a nontargeted, but rather collateral outcome, again with the rationale that AAC would provide a functional behavior as a replacement (eg, Ganz et $\left.\mathrm{al}^{28}\right)$. 
In many reviews, speech as an outcome, but usually not as a primary target of intervention, was examined. Results point mostly to negligible or small effects. ${ }^{25,28,32}$ The two reviews focused on speech outcomes were motivated by a concern often expressed in AAC literature about the potential for AAC to impede speech development, as well as a desire to investigate the potential for speech to be enhanced. ${ }^{33,34}$ These reviews indicate variable outcomes, with Schlosser and $\mathrm{Wendt}^{34}$ finding that, for individuals with autism, although modest gains in speech could not be attributable directly to AAC intervention, there was no evidence of loss of speech skills.

\section{Discussion}

\section{Reconciling evidence from the fields of AAC and autism}

The finding of the $\mathrm{NAC}^{6,7}$ that $\mathrm{AAC}$ is an emerging area, only, appears at odds with the findings from the 17 reviews presented here, even considering differences in publication periods captured: the most recent reviews in Table 1 included studies published in $2014 ;^{31,32}$ the NAC reviews were completed for two time periods, the first ending 2007, and the second covering 2007-2012. ${ }^{7}$ The main difference appears to be that studies that incorporated AAC as a component or primary part of the intervention were not grouped together as AAC interventions, but rather according to the categories of AAC devices (ie, low- and high-tech aids, including SGD, with 14 studies published from 1983 to 2007 included), and PECS (ie, this was treated separately from other aided AAC, with 13 studies published from 1994 to 2007 included), and sign instruction (with 11 studies published from 1976 to 2004 included). These were all judged to be emerging interventions in the first report, ${ }^{6}$ with further research reviewed for the second report failing to result in changing the classification for any of these forms of AAC to established interventions. ${ }^{7}$

In the current review, the number of studies judged as lacking rigor or to be of overall poor quality is perhaps further evidence of the emerging status of AAC. On the other hand, closer inspection of studies that contributed to classifying some interventions as established in the first NAC report ${ }^{6}$ reveal some included the use of AAC as part of intervention protocols. In studies of functional communication training, a type of behavioral package ${ }^{6}$ (established), for example, were the use of signs and picture systems, ${ }^{44}$ and hightech devices ${ }^{45}$ as replacements for problem (challenging) behaviors. Schedules, also an established intervention, ${ }^{6}$ are the use of task lists, often in the form of pictures (ie, AAC), to support comprehension and learning within structured activities (eg, Dettmer et $\mathrm{al}^{46}$ ). Finally, studies incorporating AAC were also considered by the NAC in determining that naturalistic teaching strategies were established. ${ }^{47}$

Regardless of the form of AAC used, interventions are multicomponent, with effective implementation requiring considerations beyond the actual modality or system used. Hence, although there have been many attempts to compare across types of AAC, the system used is part of an intervention only. Pictures used in PECS, for example, comprise one component of a comprehensive instructional package that draws on applied behavior analysis (ABA), which has a strong research base, ${ }^{6}$ implemented in a natural context. ${ }^{24}$ Lorah et $\mathrm{al}^{31}$ argued that intervention needs to address both learning how to use these AAC systems, including the newer technologies of iPods ${ }^{\circledR}$ and iPads ${ }^{\circledR}$, as well as how to communicate effectively and efficiently with them. van der Meer and Rispoli ${ }^{29}$ suggested that, in addition to behavioral approaches, greater use of naturalistic strategies that take advantage of incidental teaching moments, environmental arrangement, and following the child's lead might help extend communication to a range of functions beyond requests, including joint attention and social interactions.

A concern expressed both in the AAC and the autism literature has been the reliance on interventionists highly skilled in the teaching approaches used, resulting in potential problems in translating evidence into real-world settings. Tincani and Devis, ${ }^{27}$ for example, suggested that improvements gained through teaching PECS may fail to maintain or generalize to new communication partners and settings once highly skilled researchers, who implement many and complex teaching strategies, have completed their research. Only one review focused on training people in a child's social environment to support the use of AAC, which indicated varying levels of success across studies. ${ }^{35}$ Some studies did show strong effects, with perhaps greater potential for maintenance than when outcomes rely solely on highly skilled intervention agents, usually researchers. Within the autism literature, there is an emerging focus on training parents to implement evidence-based interventions, such as those based on ABA, or a combination of ABA and naturalistic teaching strategies. ${ }^{48}$ Furthermore, incorporating AAC into an approach combining established interventions and delivered by parents has been shown to be effective in improving the communication skills of young children with autism. ${ }^{49}$ However, as in the AAC literature, a recent autism evidence update ${ }^{50}$ indicated that more research is needed to determine if approaches considered established or emerging 
by the $\mathrm{NAC}^{6,7}$ prove to be as effective when parents are trained to deliver them.

\section{Clinical implications}

A goal of the NAC was to provide families, teachers, and other professionals supporting children with autism clear guidance for selecting evidence-based interventions. ${ }^{6,7}$ This task appears challenging in light of the large and diverse evidence bases in AAC and autism, with studies of variable quality, in addition to differences in the role assigned to various forms of AAC across the fields. In addition, the heterogeneity evident across children with autism further complicates attempts to take an evidence-based approach to intervention.

It has been suggested that there is now sufficient evidence that early and intensive intervention can ameliorate skill deficits and, thereby, ensure that children with autism will enjoy academic success. ${ }^{50}$ In particular, in the last few years there has been an increase in randomized controlled trials (RCTs), considered to provide more robust evidence for both treatment effects and their potential to generalize to the population from which samples have been drawn, than can be provided using ESCD. ${ }^{50} \mathrm{~A}$ review of this more recent research by Smith and Iadarola ${ }^{50}$ provides further support for the findings by the NAC in terms of interventions considered established, emerging, or questionable., ${ }^{6,7}$ The extent to which this research base, as well as that for AAC, as reviewed here, can inform intervention in real-world settings would seem to be complicated by limitations of even robust research designs.

A problem with RCTs is the need to obtain homogeneous samples, a challenge that has seen the proliferation of ESCD in both $\mathrm{AAC}^{1}$ and autism ${ }^{50}$ research. The results of group studies suggest that individual differences across participants may be lost in group means, although measures of variance or the reporting of individual data can reveal that some children may fail to benefit from interventions found effective for others. ${ }^{43}$ Parents and practitioners would benefit from the reporting of subgroup analyses of intervention outcomes so that treatment effects for children with the most complex communication needs can be evaluated. As a result of the extent and complexity of their social, communication, and behavioral needs, these children face challenges in achieving the rapid and consistent progress that may be attainable only by children with lesser difficulties. More detailed reporting of individual variations in intervention performance might avoid masking poor results for children with severe disability. Such reporting would provide better indicators of the quality, quantity, and consistency of evidence for intervention effects.
Individual patterns of learning are readily discernible in ESCD, an alternative to RCTs, and therefore make comparison with a child for whom a practitioner may be considering the intervention an easier task. Further, Smith and Iadarola ${ }^{50}$ noted that child variables, including preintervention IQ, age, functional language, and play, as well as intervention variables, such as treatment intensity or whether pure or eclectic approaches are used, may influence outcomes. It is these potential influences that have relevance in implementing the findings from research reviews to practice.

In light of these complex issues, families and practitioners may do well to adopt an eclectic approach. Use of AAC may prove useful when extended beyond the fairly focused aim of teaching basic communication skills, particularly requests. ${ }^{1,29}$ Promises that $\mathrm{AAC}$ can support ongoing language development ${ }^{12}$ have yet to be demonstrated convincingly for children with autism, but may be more likely if integrated into comprehensive interventions that combine evidencebased approaches, such as those using ABA and naturalistic teaching strategies in everyday contexts, as in Pivot Response Training ${ }^{11}$ and the ESDM. ${ }^{10}$ Developers of the ESDM, in suggesting that $\mathrm{AAC}$ be considered only when a child has failed to demonstrate progress in spoken language, ${ }^{10}$ may see AAC as a last-resort intervention. This approach could increase the potential for learned helplessness, challenging behavior, and missed learning opportunities. Rather, incorporating AAC into early interventions might avoid or reduce these problems. In particular, the use of visual supports, and other forms of AAC within a child's learning environments, has been suggested as good practice. ${ }^{50}$ Even children who demonstrate increasing spoken language skills stand to benefit from the additional supports that could assist with comprehension and extending language skills. For those who may not make use of visual stimuli for learning, ${ }^{43}$ providing AAC within child-led naturalistic teaching situations is unlikely to impede learning, including of speech. . $^{33,34}$

The underlying tenets of AAC research are that communication is multimodal and that individuals differ in terms of those modalities that may best suit their learning needs and preferences. ${ }^{12}$ The reliance on aided AAC has resulted in few studies including sign as a component of instruction or as a communication modality. Sign models provided within naturalistic teaching could play a valuable role for children with autism, including extending vocabulary across situations. ${ }^{51}$ Systematic reviews have tended to include only very early manual sign studies ${ }^{6}$ or those in which signs have been compared to aided systems (Table 1). Although some studies have demonstrated better outcomes using aided AAC, Gevarter et $\mathrm{al}^{22}$ found that (1) signs combined with 
speech were more effective than speech alone in increasing communication; (2) signs were more likely to result in maintenance and generalization; and (3) in comparison to PECS, signs were as effective, while being associated with more vocalizations. Such findings demonstrate the value of considering individual differences, both in terms of exploring the evidence base, and making various AAC modalities available. The provision of models using both signs and symbols on aids, for example, could maximize the potential to meet individual child learning needs and preferences. Furthermore, although it has been suggested that reduced fine motor, gesture, and imitation skills in children with autism may, to some extent, preclude the use of signing, ${ }^{20,42}$ manual sign instruction may in fact provide a highly salient and ecologically valid communication context in which to target these skills.

\section{Future directions}

In light of the potential for individual differences across children with autism to influence the success of both established and emerging interventions, research that provides details of participant characteristics would seem a priority. Of the reviews included here, most provided details of children's age and diagnosis, but only two addressed communication skills of children at the start of intervention. Schlosser and Wendt ${ }^{34}$ included only studies in which participants lacked functional speech, but no information was provided about comprehension ability. In studies included by Hart and Banda, ${ }^{26}$ children with autism were described as having limited expressive language, limited speech, being nonverbal, using only 1-2 word phrases, using a few signs, or demonstrating some vocal imitation prior to intervention. Such varied descriptions fail to provide information about possible outcome predictors for children whose communication profiles vary dramatically in terms of underlying linguistic ability and social communication. ${ }^{52}$

The potential for AAC to support ongoing language development is reliant on moving children beyond simple requests. The extent of research into the effectiveness of $\mathrm{AAC}$ in increasing requests in children with autism seems to warrant a meta-analysis. ${ }^{32}$ While such a review may further understanding of the most effective and efficient strategies to enhance communication for behavior regulation, there appears to be a greater need to evaluate eclectic teaching strategies in real-world environments that incorporate AAC as a means of addressing deficits in social-communication. Research into comprehensive and intensive programs, such as the ESDM, ${ }^{53}$ modified by incorporating various forms of AAC, would help build evidence for effective intervention for children with variable skill profiles and learning needs. ${ }^{12,43}$ In this way, AAC, when integrated with established interventions, which start early, ${ }^{50}$ could provide more socially valid outcomes than have been demonstrated to date for children with autism.

\section{Conclusion}

Extensive research across the fields of AAC and autism provides a strong evidence base to inform decisions about how and when to intervene to ensure optimal communication support for children with autism. Yet this evidence base lacks the detail needed to determine the potential for successful outcomes for children with the most significant learning needs, including those who are minimally verbal, following even those interventions with the strongest empirical support. A tendency to ignore the role of AAC or relegate it to a last-resort strategy for children who fail to show progress may be a response by autism researchers to an apparent narrow focus of AAC research. Achieving meaningful changes in the developmental trajectories of children with autism requires comprehensive and intensive approaches that have been based on a solid research foundation. AAC has a role in such approaches, but future research that broadens the lens beyond immediate communication targets, while also addressing the learning needs of children with the most severe and complex disabilities is required to converge research across autism and AAC fields.

\section{Acknowledgment}

David Trembath is supported by a National Health and Medical Research Council ECR Fellowship (GNT1071811).

\section{Disclosure}

The authors report no conflicts of interest in this work.

\section{References}

1. Ganz JB. AAC Interventions for individuals with autism spectrum disorders: state of the science and future research directions. Augment Altern Commun. 2015;31(3):203-214.

2. Rose V, Trembath D, Keen D, Paynter J. The proportion of minimally verbal children with autism spectrum disorder in a community-based early intervention programme. J Intellect Disabil Res. 2016;60(5):464-477.

3. Iacono T, Johnson H, Forster S. Supporting the participation of adolescents and adults with complex communication needs. In: Mirenda P, Iacono T, editors. Autism Spectrum Disorders and AAC. Baltimore, MD Paul H Brookes; 2009:443-478.

4. Schuler A, Baldwin M. Nonspeech communication and childhood autism Lang Speech Hear Ser Schools. 1981;12:246-257.

5. Mirenda P. Autism, augmentative communication and assistive technology: what to we really know? Focus Autism Other Dev Disabil. 2001;16 $141-151$.

6. National Autism Center. National Autism Center National Standards Report. Randolph, MA: National Autism Center; 2009. Available from: http://www.nationalautismcenter.org/reports/. Accessed March 3 2016. 
7. National Autism Center. Findings and Conclusions: National Autism Center National Standards Project, Phase 2. Randolph, MA: National Autism Center; 2015. Available from: http://www. nationalautismcenter.org/national-standards-project/results-reports/. Accessed March 3, 2016.

8. Wendt O. Research on the use of manual signs and graphic symbols in autism spectrum disorders: a systematic review. In: Mirenda P, Iacono T, editors. Autism Spectrum Disorders and AAC. Baltimore, MD: Paul H. Brookes; 2009:83-140.

9. Mirenda P, Brown K. A picture is worth a thousand words: using visual supports for augmented input with individuals with autism. In: Mirenda P, Iacono T, editors. Autism Spectrum Disorders and AAC. Baltimore, MD: Paul H. Brookes; 2009:303-332.

10. Rogers SJ, Dawson G. Early Start Denver Model for Young Children with Autism: Promoting language, learning, and engagement. New York, NY: Guilford Press; 2010.

11. Koegel RL, O’Dell MC, Koegel LK. A natural language teaching paradigm for nonverbal autistic children. J Autism Dev Disord. 1987; 17(2):187-200.

12. Romski M, Sevcik RA, Barton-Hulsey A, Whitmore AS. Eary intervention in AAC: what a difference 30 years makes. Augment Altern Commun. 2015;31(3):181-202.

13. Schlosser R, Raghavendra P. Evidence-based practice in augmentative and alternative communication. Augment Altern Commun. 2004; 20(1):1-21.

14. Schlosser R, Lee D. Promoting generalization and maintenance in augmentative and alternative communication: a meta-analysis of 20 years of effectiveness research. Augment Altern Commun. 2000;16(4): 208-226.

15. Schlosser R. Social validation of interventions in augmentative and alternative communication. Augment Altern Commun. 1999;15(4): 234-247.

16. Howlin P, Magiati I, Charman T. Systematic review of early intensive behavioral interventions for children with autism. Am J Intellect Dev Disabil. 2009;114(1):23-41.

17. Greenhalgh T, Peacock R. Effectiveness and efficiency of search methods in systematic reviews of complex evidence: audit of primary sources. BMJ. 2005;331(7524):1064-1065.

18. Schlosser RW, Balandin S, Hemsley B, Iacono T, Probst P, von Tetzchner S. Facilitated communication and authorship: a systematic review. Augment Altern Commun. 2014;30(4):359-368.

19. Ganz JB, Earles-Vollrath TL, Mason RA, Rispoli MJ, Heath AK, Parker RI. An aggregate study of single-case research involving aided AAC: participant characteristics of individuals with autism spectrum disorders. Res Autism Spectr Disord. 2011;5(4):1500-1509.

20. Ganz JB, Earles-Vollrath TL, Heath AK, Parker RI, Rispoli MJ, Duran JB. A meta-analysis of single case research studies on aided augmentative and alternative communication systems with individuals with autism spectrum disorders. J Autism Dev Disord. 2012;42(1):60-74.

21. Gevarter C, O'Reilly MF, Rojeski L, et al. Comparisons of intervention components within augmentative and alternative communication systems for individuals with developmental disabilities: a review of the literature. Res Dev Disabil. 2013;34(12):4404-4414.

22. Gevarter C, O'Reilly MF, Rojeski L, et al. Comparing communication systems for individuals with developmental disabilities: a review of single-case research studies. Res Dev Disabil. 2013;34(12): 4415-4432.

23. Ganz JB, Rispoli MJ, Mason RA, Hong ER. Moderation of effects of AAC based on setting and types of aided AAC on outcome variables: an aggregate study of single-case research with individuals with ASD. Dev Neurorehabil. 2014;17(3):184-192.

24. Preston D, Carter M. A review of the efficacy of the picture exchange communication system intervention. J Autism Dev Disord. 2009;39(10): $1471-1486$

25. Flippin M, Reszka S, Watson LR. Effectiveness of the Picture Exchange Communication System (PECS) on communication and speech for children with autism spectrum disorders: a meta-analysis. Am J Speech Lang Pathol. 2010;19(2):178-195.
26. Hart SL, Banda DR. Picture exchange communication system with individuals with developmental disabilities: a meta-analysis of single subject studies. Remed Spec Educ. 2010;31(6):476-488.

27. Tincani M, Devis K. Quantitative synthesis and component analysis of single-participant studies on the picture exchange communication system. Remed Spec Educ. 2011;32(6):458-470.

28. Ganz JB, Davis JL, Lund EM, Goodwyn FD, Simpson RL. Metaanalysis of PECS with individuals with ASD: investigation of targeted versus non-targeted outcomes, participant characteristics, and implementation phase. Res Dev Disabil. 2012;33(2):406-418.

29. van der Meer LA, Rispoli M. Communication interventions involving speech-generating devices for children with autism: a review of the literature. Dev Neurorehabil. 2010;13(4):294-306.

30. Still K, Rehfeldt RA, Whelan R, May R, Dymond S. Facilitating requesting skills using high-tech augmentative and alternative communication devices with individuals with autism spectrum disorders: a systematic review. Res Autism Spectr Disord. 2014;8(9):1184-1199.

31. Lorah ER, Parnell A, Whitby PS, Hantula D. A systematic review of tablet computers and portable media players as speech generating devices for individuals with autism spectrum disorder. J Autism Dev Disord. 2014;45(12):3792-3804.

32. Schlosser RW, Koul RK. Speech output technologies in interventions for individuals with autism spectrum disorders: a scoping review. Augment Altern Commun. 2015;31(4):285-309.

33. Millar DC, Light JC, Schlosser RW. The impact of augmentative and alternative communication intervention on the speech production of individuals with developmental disabilities: a research review. $J$ Speech Lang Hear Res. 2006;49(2):248-264.

34. Schlosser RW, Wendt O. Effects of augmentative and alternative communication intervention on speech production in children with autism: a systematic review. Am J Speech Lang Pathol. 2008;17(3): 212-230.

35. Kent-Walsh J, Murza KA, Malani MD, Binger C. Effects of communication partner instruction on the communication of individuals using AAC: a meta-analysis. Augment Altern Commun. 2015;31(4): 271-284.

36. Ganz JB, Mason RA, Goodwyn FD, Boles MB, Heath AK, Davis JL. Interaction of participant characteristics and type of AAC with individuals with ASD: a meta-analysis. Am J Intellect Dev Disabil. 2014;119(6): 516-535.

37. Horner RH, Carr EG, Halle J, McGee G, Odom S, Wolery M. The use of single-subject research to identify evidence-based practice in special education. Except Child. 2005;71(2):165-179.

38. Gersten R, Fuchs LS, Compton D, Coyne M, Greenwood C, Innocenti MS. Quality indicators for group experimental and quasiexperimental research in special education. Except Child. 2005;71(2): 149-164.

39. Scruggs T, Mastropieri MA. Summarizing single-subject research: issues and applications. Behav Modif. 1998;22:221-242.

40. Ma HH. An alternative method for quantitative synthesis of singlesubject researches: percentage of data points exceeding the median. Behav Modif. 2006;30(5):598-617.

41. Maughan DR, Christiansen E, Jenson WR, Olympia D, Clark E. Behavioral parent training as a treatment for externalizing behaviors and disruptive behavior disorders: a meta-analysis. School Psychol Rev. 2005;34(3):267-286.

42. Rose V, Trembath D, Bloomberg K. Visual attention and key word sign in children with autism spectrum disorder. J Dev Phys Disabil. 2016; 28(1):33-55.

43. Trembath D, Vivanti G, Iacono T, Dissanayake C. Accurate or assumed: visual learning in children with ASD. J Autism Dev Disord. 2015; 45(10):3276-3287.

44. Brown KA, Wacker DP, Derby KM, et al. Evaluating the effects of functional communication training in the presence and absence of establishing operations. J Appl Behav Anal. 2000;33(1):53-71.

45. Durand VM. Functional communication training using assistive devices: recruiting natural communities of reinforcement. J Appl Behav Anal. 1999;32(3):247-267. 
46. Dettmer S, Simpson RL, Myles BS, Ganz JB. The use of visual supports to facilitate transitions of students with autism. Focus Autism Other Dev Disabil. 2000;15(3):163-169.

47. Hamilton B, Snell M. Using the milieu approach to increase spontaneous communication book use across environments by an adolescent with autism. Augment Altern Commun. 1993;9:259-272.

48. Strauss K, Mancini F, Fava L. Parent inclusion in early intensive behavior interventions for young children with ASD: a synthesis of meta-analyses from 2009 to 2011. Res Dev Disabil. 2013;34(9):2967-2985.

49. Hemmeter ML, Kaiser A. Enhanced milieu teaching: effects of parent-implemented language intervention. J Early Intervention. 1994; 18(3):269-289.
50. Smith T, Iadarola S. Evidence base update for autism spectrum disorder J Clin Child Adolesc Psychol. 2015;44(6):897-922.

51. Tan XY, Trembath D, Bloomberg K, Iacono T, Caithness T. Acquisition and generalization of key word signing by three children with autism. Dev Neurorehabil. 2014;17(2):125-136.

52. Tager-Flusberg H, Kasari C. Minimally verbal school-aged children with autism spectrum disorder: the neglected end of the spectrum. Autism Res. 2013;6(6):468-478.

53. Dawson G, Rogers S, Munson J, et al. Randomized, controlled trial of an intervention for toddlers with autism: the early start denver model. Pediatrics. 2010;125(1):e17-e23.

\section{Publish your work in this journal}

Neuropsychiatric Disease and Treatment is an international, peerreviewed journal of clinical therapeutics and pharmacology focusing on concise rapid reporting of clinical or pre-clinical studies on a range of neuropsychiatric and neurological disorders. This journal is indexed on PubMed Central, the 'PsycINFO' database and CAS, and is the official journal of The International Neuropsychiatric Association (INA). The manuscript management system is completely online and includes a very quick and fair peer-review system, which is all easy to use. Visit http://www.dovepress.com/testimonials.php to read real quotes from published authors.

Submit your manuscript here: http://www.dovepress.com/neuropsychiatric-disease-and-treatment-journal 